University of Warwick institutional repository: http://go.warwick.ac.uk/wrap This paper is made available online in accordance with publisher policies. Please scroll down to view the document itself. Please refer to the repository record for this item and our policy information available from the repository home page for further information.

To see the final version of this paper please visit the publisher's website. Access to the published version may require a subscription.

Author(s): Steve Fuller Article Title: Social Epistemology: A Philosophy for Sociology or a Sociology of Philosophy?

Year of publication: 2000 Link to published version: http://dx.doi.org/10.1177/S0038038500000353

Publisher statement: None 


\title{
Social Epistemology: A Philosophy for Sociology or a Sociology of Philosophy?
}

\section{Steve Fuller}

Department of Sociology

University of Warwick

\author{
Randall Collins, The Sociology of Philosophies: A Global Theory of Intellectual Change, Cambridge, \\ Massachusetts: Harvard University Press, 1998, $\mathfrak{E} 30.95$ xxi + 1098 pp. (ISBN 0-674-81647-1) \\ Alvin I. Goldman, Knowledge in a Social World, Oxford: Oxford University Press, 1999, £16.99 \\ paperback, xiii + $407 \mathrm{pp}$. (ISBN 0-19-823820-7)
}

\section{Social epistemology versus social ontology}

About a dozen years ago I started a journal and wrote a book, both with the name social epistemology (Fuller 1988; Fuller 1996). In the intervening years a few intrepid philosophers and sociologists have tried to map this area, and the two books under review represent two very important, yet very different, efforts from both sides of the disciplinary divide. But before proceeding further, I should say that 'social epistemology' is not the only rubric that philosophers and sociologists have used to map a common conceptual space. To be sure, in the days when Popper and Wittgenstein aroused passions, 'philosophy of the social sciences' could lay fair claim to that goal. Much of the work of Gouldner, Habermas, Foucault and Bourdieu is also easily interpreted as exercises in social epistemology, as each in its own way theorises the place of the knower in the production of social knowledge. However, at the same time, there has been considerable resistance to social epistemology amongst both philosophers and sociologists in Britain. (It is no coincidence that Collins and Goldman are American.) Instead, what may be called social ontology turns out to be the terms in which philosophy and sociology have sought common ground, and much of what today passes for 'social theory' - especially that which takes Anthony Giddens as a significant presence - falls under this rubric (Fuller 1995).

Perhaps the most striking difference between social ontology and social epistemology is their attitude towards the relationship between philosophy and sociology. Generally speaking, that relationship can be envisaged in four distinct ways, which are listed below, along with the relevant classical social theorists. Social epistemologists occupy positions (1) and (2), social ontologists (3) and (4).

(1) Philosophy relates to sociology as form to matter. If philosophy articulates the idea of the good society, sociology establishes the conditions under which it can be realised. Philosophy first guides but is then superseded by sociology. This view is most strongly associated with Marx, with earlier resonances in Hegel and Comte, and is largely presupposed by Collins. I must confess my own sympathies with this position, which sees philosophy and sociology as two overlapping stages in what is essentially the same inquiry.

(2) Philosophy relates to sociology as rational to irrational. There is a division of labour between 
the two disciplines, which still gives sociology much to do, since most of social life regularly falls short of the rational ideals articulated by philosophers and officially espoused by social agents. Pareto is the standard-bearer here, though Mannheim's sociology of knowledge is probably the best known variant. Goldman speaks from the philosophical side of this divide.

(3) Philosophy relates to sociology as metaphysics to physics. Here philosophy underwrites the validity of much, most or all extant empirical social research by demonstrating the existence of a domain of reality towards which social inquiry is directed. This demonstration is characteristically 'transcendental', in that it proceeds from the assumptions that social research could not take place at all if reality were not constituted in a certain way. This is how Durkheim originally carved out a niche for sociology in the French academy, and 'critical realists' following the lead of Roy Bhaskar continue to justify a normatively inspired structural Marxism.

(4) Philosophy relates to sociology as conscious to unconscious. In this guise, sociology articulates the logic of everyday practices that constitute the social order, which are not normally dignified with comment, much less codification. It charts realms of 'local knowledge' and 'situated reasoning', which philosophers have traditionally dismissed as trivial or irrational. Weber's interest in the meaning that social agents attach to their actions falls into this category, which has been since then taken up by symbolic interactionists and ethnomethodologists. But perhaps the most interesting work in this vein comes from feminist and postcolonial sociologists who turn this perspective into an opportunity to give voice to subaltern groups.

Focusing on (3) and (4), we can immediately say why neither Collins nor Goldman is a social ontologist. As opposed to (3), neither assumes that the actual state of knowledge production tells us something deep about its conditions of possibility. Rather, both take the actual as the basis for inferring conditions under which knowledge may flourish and diminish. In other words, Collins and Goldman presume that knowers normally do not know how to know, and hence their collective efforts to date do not constitute all there is to know: a special inquiry into the matter is therefore needed (i.e. a social epistemology). Collins proceeds in terms of a comparative historical sociology of philosophical cultures in European and Asian spheres of influence over the last 2,500 years, whereas Goldman argues in largely aprioristic terms about the sorts of authority structures and communication networks that will tend to encourage and inhibit the production of reliable knowledge.

As opposed to (4), neither Collins nor Goldman gives much credence to informal or unofficial knowledge. This is particularly striking in Collins's case, given the comprehensively empirical character of his project. While Collins's book purports to provide a 'global theory of intellectual change', it is nevertheless grounded in a content analysis of standard histories of philosophy, which tend to presume that philosophy is something done by philosophers for other philosophers. Consequently, the traditionally formal branches of the discipline - logic, metaphysics and epistemology - lead Collins's narrative to such an extent that Niccolo Machiavelli, whose concerns were grounded in the practice of law, politics and ethics, receives hardly a mention. For his part, Goldman takes for granted that knowledge in a complex world entails relatively discrete expertises. The main questions for him are how to identify the experts relevant to a given case and the degree to which one should trust their judgement. Interestingly, Goldman tends to conflate the ideas of 'marginal' and 'novel' forms of knowledge, which would seem to deny the possibility that some quite legitimate ways of knowing remain out of the mainstream for long periods of time. 


\section{A tale of two social epistemologies}

In highlighting the sense in which both Collins and Goldman are social epistemologists, we begin to see some very significant points of divergence. Goldman assumes a pre-sociological sense of 'the social' as the aggregation of individuals. Accordingly, social life occurs only in observable interactions between individuals. Upbringing, training, let alone spatiotemporally distributed patterns of structural domination, do not figure in Goldman's theory. Thus, all of the interesting properties of epistemic communities turn out to be either the intended or unintended consequences of such interaction. While hardly a novel view of the relationship between the individual and the social, it presupposes an indeterminacy of the social that is lacking in the individual. Individuals are presumed to have clearly identified psychological and biological properties prior to their engagement with others, whereas societies have no clear identity before they are constituted by specific individuals.

While Goldman gladly concedes this point, my original formulation of social epistemology drew attention to two logical fallacies, that of composition and division, which together deny the possibility of either exhaustively explaining the whole (for example, a society) in terms of its parts (for example, the society's members) or vice versa (Fuller 1988:xii-xiii). It follows that a social epistemology based on a well-bounded conception of the individual knower will be substantially different from one that proceeds from a well-bounded conception of society. Of course, there is a broadly 'constructivist' alternative to this polarity, namely, that the conditions for individual and collective knowledge mutually define each other. This more reflexive approach to social epistemology is captured by Collins's distinction between 'organisational' and 'intellectual' leaders in the history of philosophy. For example, in his capacity as organisational leader, Fichte defined the field's research frontier in the early nineteenth century, so as to render his teacher Kant the focus for all subsequent debate. In effect, Fichte gave philosophy a new sense of purpose as the bulwark of the German university system and by redefining the significance of its past intellectual leaders like Kant.

Another point of divergence concerns what each takes to be the point, or 'function', of the knowledge system. Goldman is loud and clear: the overarching goal is the production of reliable truths about matters of social concern by the most efficient means possible. At one level of analysis, one which Goldman himself promotes, this is the only point of the knowledge system qua knowledge system. Of course, science, law, journalism, education and other knowledge-oriented institutions have multiple social functions. But from Goldman's standpoint, these can interfere with its specifically epistemic goals. This viewpoint presupposes that, in matters of knowledge, the ends always justifies the means. Goldman allows that the best knowledge producing system may be one that concentrates its resources on a few elite inquirers who communicate and otherwise implement their findings in ways that provide the most benefit for society, by manipulating most of the population most of the time, perhaps because (as, say, Plato thought) people find the truth hard to take, both cognitively and emotionally. Here readers are invited to consult Goldman's positive remarks about 'epistemic paternalism', which justifies censorship and deception if dissemination of the truth is likely to result in social unrest.

Goldman's orientation to knowledge production is reminiscent of explanations of wealth production in advanced capitalism, where one finds little concern for who actually participates in the process and how they are organized. Rather, maximum productivity per se is supposed to be good for everyone, as the knowledge produced somehow manages to filter down to those most in need of it. In contrast, Collins envisages knowledge production as a thoroughly collective process - a system of densely networked 'interaction ritual chains', in Goffman's phrase. Although Collins periodically alludes to the larger social and physical environment which shapes and is shaped by 
the intellectual world, he tends to treat intellectual life as both self-organising and self-oriented. He focuses less on sheer productivity than on the refinement of its products. Specifically, the more philosophy has been in control of its own agenda, the more abstract and reflexive it has been. However, this has reflected either the very high or very low social status of the field. The interesting interpretive question concerns how one knows which is which. For example, Collins sees the general increase in philosophical abstraction in the West after the Scientific Revolution as a case of retreat.

Goldman and Collins also instructively differ over what Kuhn (1977) originally called 'the essential tension' between tradition and innovation: Goldman valorises the former, Collins the latter. Much like Kuhn himself, Goldman holds that social epistemology needs to explain, not how knowledge systems generate new ideas and discoveries, but how they come to provide reliable access to socially significant aspects of reality: i.e. the conditions for 'normal science'. It is worth observing here that while Goldman shows no signs of having conducted what sociologists would regard as empirical research, his terms of reference are nevertheless consonant with the recent stress in social studies of science on the 'resilience' and 'durability' of mundane laboratory practices (Biagioli 1999).

However, I must confess sympathy for Collins's alternative framing of the issue, which focuses on how a highly disciplined knowledge practice like philosophy enables zones of creativity, mainly by allowing practitioners to address several audiences at work in the course of systematically solving a set of problems. Of course, as Collins rightly stresses, this creativity is often lost in the teaching of philosophy, which reduces each major figure's contribution to a position in a neverending chessmatch. In this context, Collins provocatively suggests that the general sociological explanation for the 'depth' of philosophical problems (i.e. their resistance to clear solutions) may be that the discipline's collective attention span is so limited that subtle formulations are easily lost and hence in continual need of reinvention.

For Goldman, the ultimate normative question is whether the knowledge produced by a given community can command the assent of all sincere knowers, a goal that should be familiar to sociologists from Habermas, which Goldman interprets in terms of the ability of knowledge claims to pass a wide range of validity checks that are conducted outside the original community. Goldman does not presume that knowledge producers are pristine intellects; rather, the validity checks somehow manage to filter out the corrupting influences. In contrast, Collins treats communities as embodying or enacting the knowledge they produce. Consequently, the idea of independent validity checks is alien to his thinking. The key questions for him are whether the selfrecognised knowledge producers dictate their own inquiries and how the products of those inquiries are transmitted to and transformed by later generations of knowledge producers.

\section{Conclusion: divining the end of knowledge and a future for social epistemology}

There is one difference between Goldman's and Collins's orientations to social epistemology that explains all their other differences. Goldman takes for granted that epistemic virtue - 'truth' - can be distinguished, not only analytically, but also substantively, from other normative virtues such as 'goodness', 'justice,' 'beauty', 'efficacy' and 'power'. Consequently, he sees the social epistemologist as designing institutions for the reliable production of knowledge, assuming that any such institution would have a knock-on effect for the promotion of the other virtues. In effect, he raises the legendarily 'autonomous' character of organised inquiry to a policy imperative. But from Collins's standpoint, Goldman is simply reifying the distinction between epistemology and ethics, which emerged as philosophy became a specialised academic field in the 
late nineteenth century. However, Goldman's move involves more than forgetting the past: it also adumbrates a range of possible futures for the relationship between systematic knowledge and the social practices that constitute it.

As mentioned earlier, Goldman appears willing to let the need to preserve autonomous inquiry justify a paternalistic attitude to those members of the larger society who are unable to assimilate new knowledge in a duly 'rational' fashion. However, with the weakening of the nationstate in these neo-liberal days, it is more likely that purportedly reliable knowledge processes will be codified as computer algorithms, subject to patents and traded on the stock market. After all, the value of the bids that speculators make on particular stocks rests ultimately on the performance of the companies that underlies them. Indeed, this is a reasonable extension of Goldman's own tendency to reformulate classic epistemological issues in terms of problems in rational choice theory and cognitive science.

But there is also a dystopic future implicit in Collins's social epistemology, which results from knowledge systems becoming victims of their own success. As the number of people participating in organised inquiry increases and the knowledge they produce figures more prominently in the larger processes of social reproduction, the possibilities for intellectual innovation are pushed to the margins. Those who cannot make it in a highly competitive and bureaucratised knowledge system must seek support in the less official arenas of free-lance writing, business and political activism. Thus, Collins recounts that Europe's original 'knowledge society' was late sixteenthcentury Spain, which contained thirty-two universities that were attended by 3 per cent of the country's male population. (That figure was only matched by the United States in the early twentieth century.) Spain was then reaching the limit of its imperial reach. It also fostered a 'Golden Age' in literature, epitomised by the work of Cervantes. However, this literary activity existed outside, and largely in opposition to, academia. Indeed, when Bacon, Descartes and other leaders of the Scientific Revolution wished to refer to the scholastic orthodoxy, they typically turned to tracts by Spanish academics. Collins periodically intimates that we in the West currently live in just such a society; hence, innovation flourishes in computer programming and science fiction writing. If history is to be believed, these para-academic pursuits are sowing the seeds of the next intellectual revolution.

Goldman and Collins epitomise the rather divergent directions that philosophers and sociologists have taken the research programme of social epistemology. Goldman stresses the efficient production of knowledge at the expense of querying who participates in the process and the extent to which a given epistemic community represents the interests of the society that sustains it. Collins illustrates the complementary case of defining the conditions of participation in the knowledge system, while downplaying the efficacy that the system's products has on the larger society. Since Goldman and Collins generally presume that the community of knowledge producers is a well-defined subset of any given society, they are unable to address how the nature of knowledge would change, were more and different people officially involved in its production. To be sure, in both cases, this is largely the result of simplifying assumptions they have had to make to bring their heroic projects to fruition. Nevertheless, the promise of social epistemology will only be realised once a theorist is able to connect questions about participation and production in the knowledge system without supposing the optimality of the prevailing linkages.

REFERENCES

Biagioli, M. (ed.) 1999. The Science Studies Reader. London: Routledge.

Fuller, S. 1988. Social Epistemology. Bloomington: Indiana University Press.

Fuller, S. 1995. 'Is There Life for Sociological Theory after the Sociology of Scientific Knowledge?' Sociology 29:159-66. 
Fuller, S. 1996. 'Recent Work in Social Epistemology'. American Philosophical Quarterly 33:149-66. Kuhn, T. 1977. The Essential Tension. Chicago: University of Chicago Press.

Biographical note: STEVE FULLER is Professor of Sociology at the University of Warwick. He founded the research programme of social epistemology in 1987 with a journal of that name, and is the author of six books, the latest of which are The Governance of Science: Ideology and the Future of the Open Society (2000) and Thomas Kuhn: A Philosophical History for Our Times (2000).

Address: Department of Sociology, University of Warwick, Coventry CV47AL, and on e-mail at: s.w.fuller@warwick.ac.uk. 